\title{
SCIENTIFIC REPORTS

\section{OPEN Investigation of fragmentation behaviours of isoquinoline alkaloids by mass spectrometry combined with computational chemistry}

\author{
Zhixing Oing ${ }^{1,2,6}$, Yuqin $\mathrm{Xu}^{4,6}$, LiuyiYu ${ }^{3}$, Jinghong Liu ${ }^{1}$, Xiuqiong Huang ${ }^{1}$, Zhaoshan Tang ${ }^{5}$, \\ PiCheng ${ }^{1 \star}$ \& Jianguo Zeng ${ }^{1,5^{*}}$
}

Isoquinoline alkaloids, which are one of the most important types of alkaloids, are extensively distributed in herbal medicines. However, systematic and comprehensive investigations of the fragmentation behaviours of isoquinoline alkaloids have rarely been reported. Therefore, the goal of the present study is to simultaneously investigate the collision-induced dissociation patterns and the corresponding mechanism of isoquinoline alkaloids by mass spectrometry (MS) combined with computations. Nineteen types of isoquinoline alkaloids ( 66 compounds) were used as references to identify the characteristic fragmentation behaviours by quadrupole time-of-flight mass spectrometry (Q-TOF/MS) in positive electrospray ionization (ESI) mode. These types of isoquinoline alkaloids were divided into three categories primarily by the characteristic $\left[M-N H R_{1} R_{2}\right]^{+}\left(R_{1}\right.$ and $R_{2}$ represent the substituent groups of the $\mathrm{N}$-atom) fragment ions. High- and low-abundance $\left[\mathrm{M}-\mathrm{NHR} \mathrm{R}_{1} \mathrm{R}_{2}\right]^{+}$ions were observed respectively for type I (1-13) and type II (14-29) alkaloids, respectively; however, the characteristic fragments were not detected for type III alkaloids (30-66) because of the existence of a $p-\pi$ conjugated system. Each type of alkaloid was further classified by its characteristic fragmentation patterns and fragment ions. In addition, isoquinoline alkaloid with vicinal methoxy and hydroxy, vicinal methoxy, methylenedioxy, methoxy, and quaternary $\mathrm{N}$-methyl groups could form the characteristic fragments by the loss of $\mathrm{CH}_{3} \mathrm{OH}, \mathrm{CH}_{4}, \mathrm{CH}_{2} \mathrm{O}$ or $\mathrm{CO}, \mathrm{CH}_{3}$ and $\mathrm{CO}$, and $\mathrm{CH}_{3}$ moieties, respectively. The mechanisms of some interesting fragmentation behaviours, such as the formation of $\left[\mathrm{M}-\mathrm{NH}_{3}\right]^{+}$and $\left[\mathrm{M}-\mathrm{CH}_{3}\right]^{+}$fragment ions, were further demonstrated by computational chemistry. These characteristic fragmentation behaviours and fragment ions of isoquinoline alkaloids provide a solid foundation for the rapid and high-efficiency structural elucidation of similar metabolites in plant-derived medicines.

Isoquinoline alkaloids, such as the analgesic agents morphine and codeine, the anticancer and antitussive drug noscapine, and the antimicrobial agents berberine and sanguinarine, are derived biosynthetically from the amino acid tyrosine in the plant kingdom (Fig. 1) ${ }^{1,2}$. They are distributed extensively in herbal medicines in many parts of the world ${ }^{3}$. Modern pharmacology studies have demonstrated that isoquinoline alkaloids have a wide range of biological activities, such as antimicrobial, antiviral, anticancer, antiproliferative, and antiplasmodial activities and acetylcholinesterase inhibitory and pain-killing effects ${ }^{4,5}$. To date, more than 4000 isoquinoline alkaloids have been detected from at least 10 plant families, namely, Papaveraceae, Berberidaceae, Rutaceae, Menispermaceae, Alangiaceae, Fabaceae, Ranunculaceae, Lauraceae, Annonaceae, and Fumariaceae ${ }^{3}$. In addition to these well-known compounds, a series of isoquinoline alkaloids, which may have potential biological activities, are still unknown. Further research to identify their structures in plant-derived medicines is necessary.

\footnotetext{
${ }^{1}$ Hunan Key Laboratory of Traditional Chinese Veterinary Medicine, Hunan Agricultural University, Changsha, 410128, China. ${ }^{2}$ College of Food Science and Technology, Hunan Agricultural University, Changsha, 410128, China. ${ }^{3}$ School of pharmacy, Hunan University of Chinese Medicine, Changsha, 410208, China. ${ }^{4}$ Department of pharmacy, First Affiliated Hospital of Hunan University of Chinese Medicine, Changsha, 410007, China. ${ }^{5}$ Micolta Bioresource Inc., Changsha, 410005, China. ${ }^{6}$ These authors contribution equally: Zhixing Qing and Yuqin Xu. *email: picheng@ hunau.edu.cn; zengjianguo@hunau.edu.cn
} 


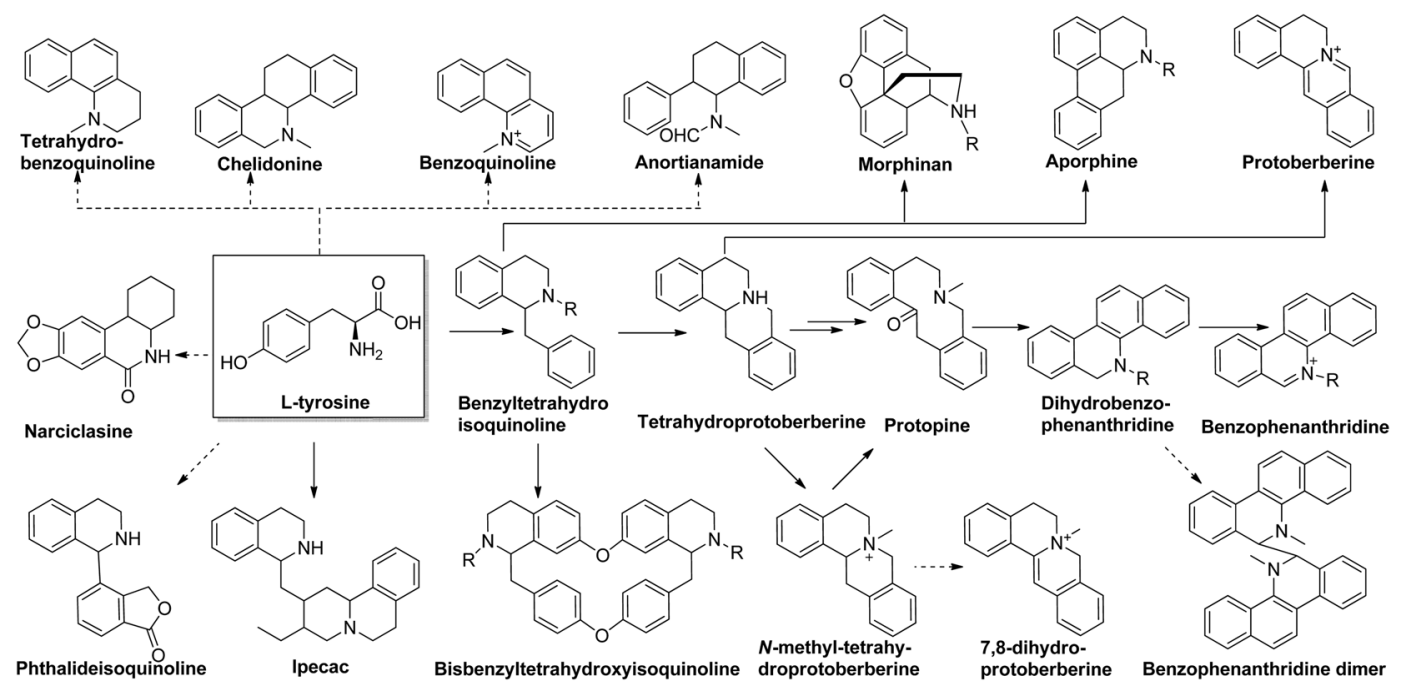

Figure 1. Biosynthetic pathways to 19 types of isoquinoline alkaloids (the solid arrow indicates the verification pathways, and the dashed arrow represents the proposed pathways).

The resurgence of interest in the plant kingdom as an important source for discovering new chemotherapeutic drugs or lead compounds has prompted the urgent need for modern mass spectrometric methods that enable rapid screening and characterization of these compounds. In a specific plant, analogues with the same skeleton but different substituent groups are biosynthesized synchronously in differing amounts though specific biosynthetic pathways ${ }^{6}$. Since these analogues typically display similar tandem mass spectrometry (MS/MS) fragmentation patterns, investigation of the fragmentation behaviours of well-characterized references is a valid approach for determining the structure of unknown analogues ${ }^{7}$. However, in some previous studies ${ }^{8-11}$, only limited isoquinoline alkaloids were determined in plant medicine by their MS/MS data. One of the main reasons is the lack of enough reference samples for investigating the fragmentation behaviours. Therefore, in the present study, the fragmentation patterns of 19 types of isoquinoline alkaloids (66 compounds) were systematically and comprehensively investigated to provide a solid foundation for identifying analogues in plant-derived medicines.

In some previous studies, the fragmentation behaviours or characteristic fragment ions of benzyltetrahydroisoquinoline $e^{12-15}$, aporphine $\mathrm{e}^{10,14-16}$, tetrahydroprotoberberine $\mathrm{e}^{8,10,12-15,17}$, protopine $\mathrm{e}^{10,14,15}$, protoberberine $e^{8,10,11,14,15,17-19}, N$-methyltetrahydroprotoberberine ${ }^{14,15}$, dihydrobenzo- phenanthridine $e^{14,15}$, benzophenanthridine $e^{14,15,20,21}$, chelidonine $e^{22}$, morphine $e^{23}$, narciclasine ${ }^{24}$, phthalideisoquinoline ${ }^{25}$, ipecac ${ }^{26}$, and bisbenzyltetrahydroxyisoquinoline ${ }^{27}$ have been investigated. However, comparative studies on the fragmentation pathways of these isoquinoline alkaloids have rarely been reported, which leads to the neglect of some interesting and characteristic fragmentation patterns. In this study, the fragmentation behaviours of 19 types of isoquinoline alkaloids were simultaneously investigated, and their fragmentation pathways were comprehensively and systematically compared. Some interesting fragmentation patterns and characteristic fragments, such as the low-abundance $\left[\mathrm{M}-\mathrm{NHR}_{1} \mathrm{R}_{2}\right]^{+}$fragment ions for tetrahydroprotoberberine, $N$-tetrahydroproto- berberine, protopine, morphine, and phthalideisoquinoline-type alkaloid, were observed for the first time.

Electrospray ionization mass spectrometry (ESI-MS) is an ideal tool to study the dissociation reactions of organic compounds and has been widely applied to investigate the fragmentation pathways of isoquinoline alkaloids ${ }^{14-17}$. However, the fragmentation mechanism in ESI-MS has not yet been well studied. Therefore, in this present study, some important and interesting mechanisms of dissociation reactions of isoquinoline alkaloids were primarily proposed. In addition, density functional theory (DFT)-based calculations were performed to support the proposed mechanism.

\section{Results and Discussion}

Fragmentation behaviours of benzyltetrahydroisoquinoline, aporphine, ipecac, chelidonine and bisbenzyltetrahydroisoquinoline. In the MS/MS investigation of benzyltetrahydroisoquinoline (1-7), aporphine (8-9), ipecac (10-11), chelidonine (12) and bisbenzyltetrahydroisoquinoline alkaloid (13) (type I), the high-abundance fragments $[\mathrm{M}-45.0578]^{+}\left(\left[\mathrm{M}-\mathrm{NH}\left(\mathrm{CH}_{3}\right)_{2}\right]^{+}\right),[\mathrm{M}-31.0422]^{+}\left(\left[\mathrm{M}-\mathrm{NH}_{2} \mathrm{CH}_{3}\right]^{+}\right)$ and $[\mathrm{M}-17.0265]^{+}\left(\left[\mathrm{M}-\mathrm{NH}_{3}\right]^{+}\right)$were observed according to the different substituent groups on the $\mathrm{N}$-atom. These fragment ions are attributed to the loss of neutral $N_{H} R_{1} R_{2}\left(R_{1}\right.$ and $R_{2}$ represent the substituent groups on the $N$-atom) moiety from the protonated molecules. In the MS/MS spectra of alkaloids 1-13 (Fig. S1), the high- abundance ions at $m / z 269.1180,269.1169,285.1137,299.1279,271.0984,285.1134,299.1281,297.1114$, $311.1279,450.2633,464.2797,323.0893$ and 592.2707 were detected, respectively, which corresponded to the loss of an $\mathrm{NHR}_{1} \mathrm{R}_{2}$ moiety from the protonated molecular weights at $m / z 286.1445,300.1582,316.1545,330.1714$, 288.1233, 302.1394, 316.1552, 342.1701, 342.1696, 467.2898, 481.3063, 354.1313 and 623.3121 (Fig. 2). The characteristic fragmentation behaviours and corresponding distinctive fragment ions play a diagnostic role in the discrimination of other alkaloid types ${ }^{12-16}$. 

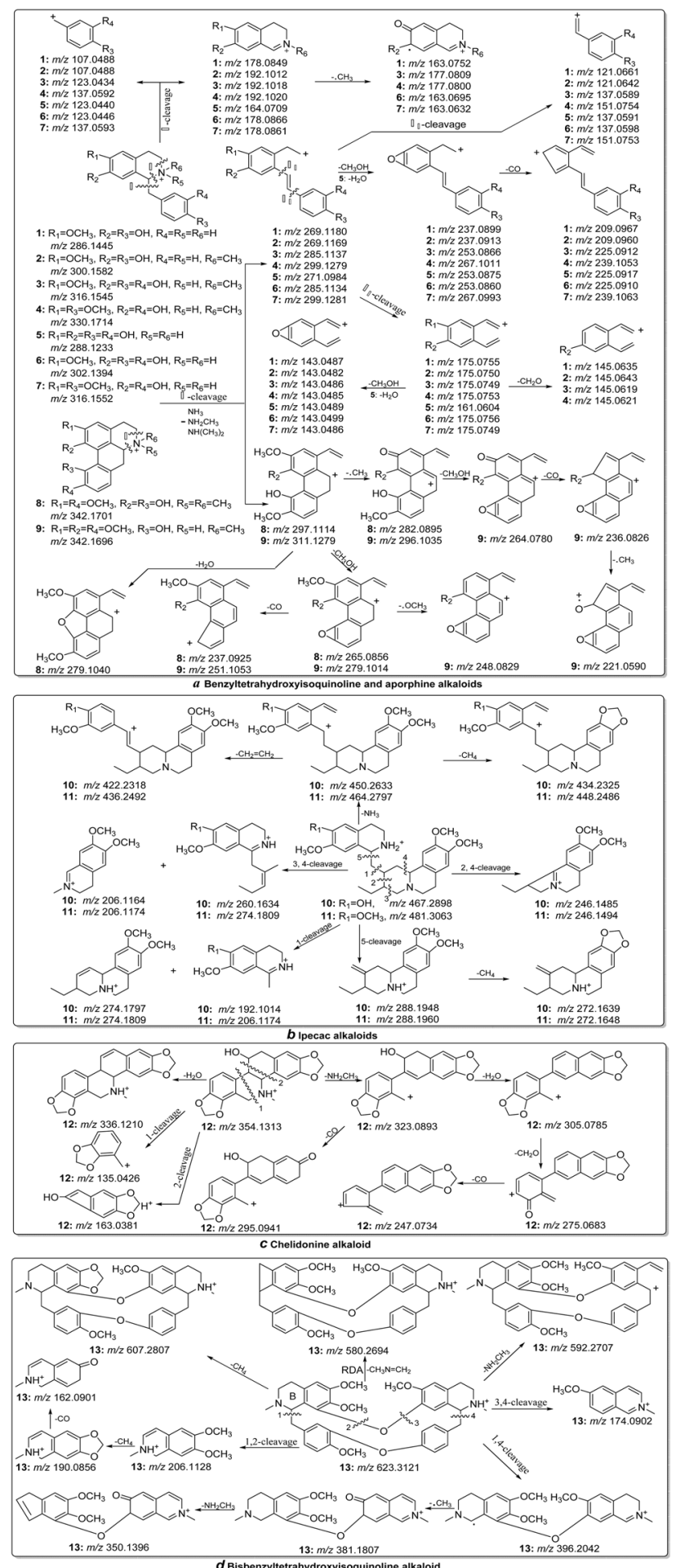

Figure 2. The proposed fragmentation behaviours of benzyltetrahydroisoquinoline and aporphine (a), ipecac (b), chelidonine (c), and bisbenzyltetrahydroisoquinoline (d).

The mechanism for the formation of $\left[\mathrm{M}-\mathrm{NHR} \mathrm{R}_{2}\right]^{+}$fragment ions for type I isoquinoline alkaloids has rarely been investigated and reported. In this study, a representative compound (alkaloid $\mathbf{1}$ ) was selected as a model to demonstrate the most favoured protonation site and possible fragmentation mechanism. The full-scan positive ion ESI mass spectrum of alkaloid 1 displayed a protonated molecule at $m / z 284.1445$, which subsequently gave the highly abundant product ion at $\mathrm{m} / z 269.1180$ by collision-induced dissociation (Fig. 3A). The structure contains different protonation sites, such as nitrogen atom, phenyl rings $\mathrm{A}$ and $\mathrm{C}$, and oxygen atoms of methoxy and hydroxy groups. Each possible protonation site of alkaloid 1 was optimized at the RB3LYP/6-31 G $(d)$ level. The relative energy of these structures was calculated, as shown in Table 1 . The computational results indicated that 

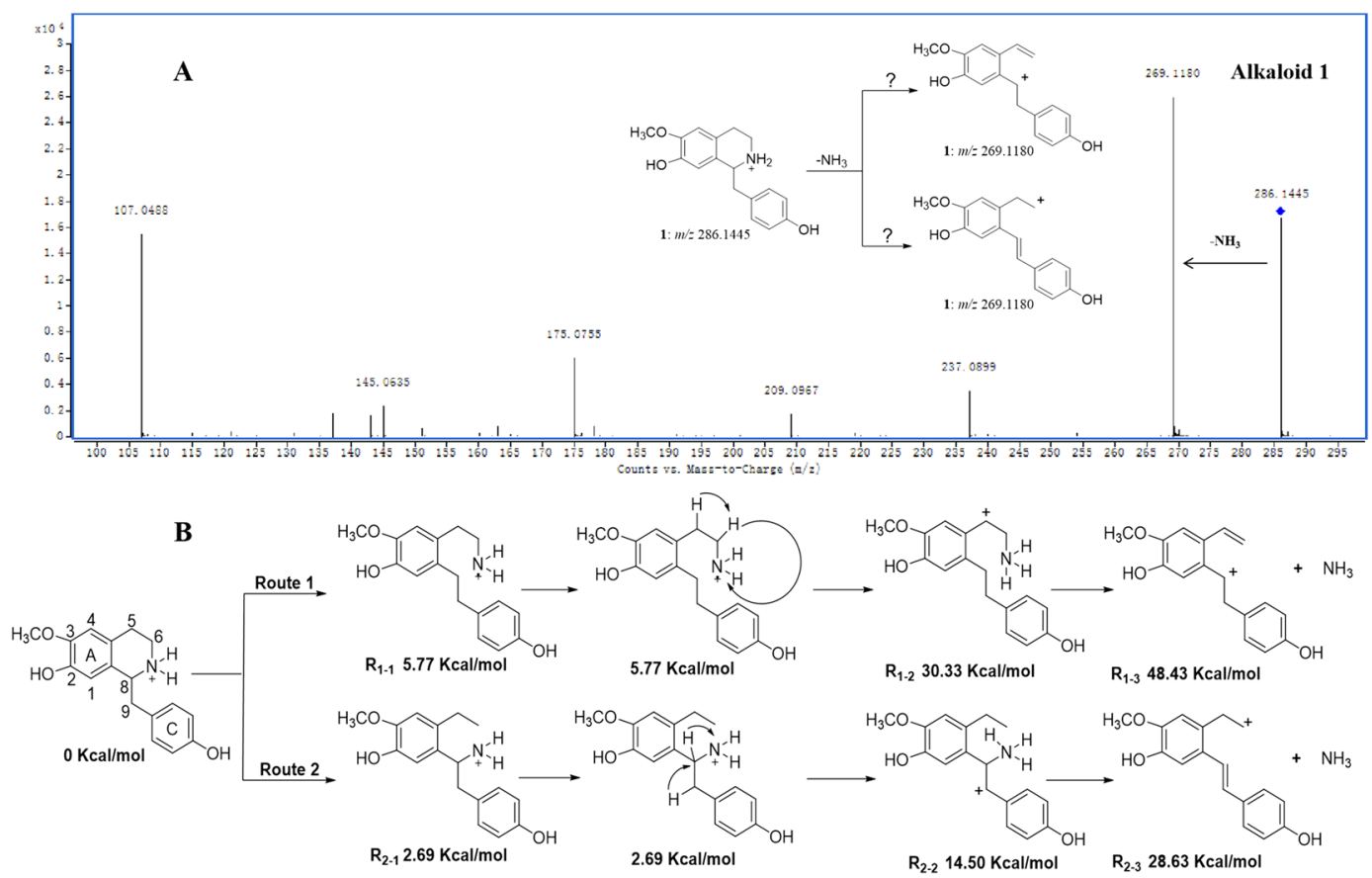

Figure 3. The MS/MS spectrum of alkaloid $\mathbf{1}$ (A) and the two proposed fragmentation mechanisms for the loss of an $\mathrm{NH}_{3}$ moiety $(\mathbf{B})$.

\begin{tabular}{|c|c|c|}
\hline Structure & Site of protonation & Relative energy (kcal/mol) \\
\hline \multirow{6}{*}{ 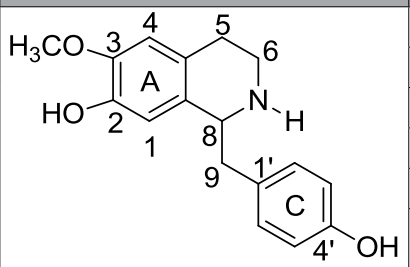 } & Nitrogen & 0.0 \\
\hline & Phenyl ring A & 24.77 \\
\hline & Phenyl ring $\mathrm{C}$ & 34.19 \\
\hline & Oxygen of 3- $-\mathrm{OCH}_{3}$ & 47.69 \\
\hline & Oxygen of 2-OH & 52.55 \\
\hline & Oxygen of $4^{\prime}-\mathrm{OH}$ & 60.84 \\
\hline
\end{tabular}

Table 1. Relative energies of structures with different protonation sites of alkaloid $\mathbf{1}$.

nitrogen is the most favoured protonation site because the protonated molecule has the lowest energy, which agrees with previous reports ${ }^{14-17}$.

The neutral loss of $\mathrm{NH}_{3}$ from the protonated molecule at $m / z 284.1445$ was triggered by the arrival of a proton, which is described as a so-called dissociative protonated site. Two possible fragmentation mechanisms (Fig. 3B) were proposed for the competitive proton transfer reactions to explain the formation of the molecular ion peak at $m / z 269.1180$. In pathway 1 , cleavage of the $\mathrm{N}-\mathrm{C}_{8}$ bond by proton-induced dissociation leads to formation of the active intermediate $\left(\mathbf{R}_{1-1}\right)$ first. Then, the hydrogen atom transfers from C-5 to the $\mathrm{N}$-atom through a three-membered-ring transition state to form $\mathbf{R}_{1-2}$. Finally, the neutral loss of $\mathrm{NH}_{3}$ was observed by cleavage of the bond between C-6 and the $\mathrm{N}$-atom and formation of the fragment ion $\left(\mathbf{R}_{1-3}\right)$. In pathway 2, cleavage of the $\mathrm{N}-\mathrm{C}_{6}$ bond leads to formation of the active intermediate $\left(\mathbf{R}_{2-1}\right)$ first. Then, the hydrogen atom migrates from C-9 to the $\mathrm{N}$-atom formation in the transition state $\mathbf{R}_{2-2}$. Finally, the neutral loss of $\mathrm{NH}_{3}$, which gave the fragment ion $\left(\mathbf{R}_{2-3}\right)$, was also detected through the cleavage of the bond between $\mathrm{C}-8$ and the $\mathrm{N}$-atom. It is difficult to deduce whether pathway 1 or 2 is the more reasonable fragment pathway without theoretical calculations. The relative energies of $\mathbf{R}_{\mathbf{1 - 1}}, \mathbf{R}_{\mathbf{1 - 2}}$, and $\mathbf{R}_{\mathbf{1 - 3}}$ are $5.77,30.33$ and $48.43 \mathrm{kcal} / \mathrm{mol}$, which are $3.08,15.83$ and $19.80 \mathrm{kcal} / \mathrm{mol}$ higher than those of $\mathbf{R}_{2-1}, \mathbf{R}_{2-2}$, and $\mathbf{R}_{2-3}$, respectively. These results suggest that pathway 2 is the more reasonable fragmentation mechanism for the neutral loss of $\mathrm{NH}_{3}$ because pathway 1 needs to overcome a higher energy barrier. The schematic potential energy surface for the proposed fragmentation mechanism is given in Fig. S2 to quantitatively describe the energy requirement of the reaction.

In addition to the above characteristic fragmentation pattern, several common fragmentation behaviours were observed for these five types of isoquinoline alkaloids. Alkaloids with vicinal methoxy and hydroxy groups could produce the characteristic fragments by the neutral loss of $\mathrm{C}_{3} \mathrm{OH}$ molecule. In the MS/MS spectra of alkaloids 1, 2, 3, 4, 6, 7, 8 and 9 (Fig. S1), the fragment ions at $m / z 175.0755,175.0750,175.0749,175.0753$, $175.0756,175.0749,265.0856$ and 279.1014 corresponded to the loss of a $\mathrm{CH}_{3} \mathrm{OH}$ moiety from their mother fragment ion (Fig. 2(a)). Alkaloids with vicinal methoxy groups could produce the fragment ions by the loss of a $\mathrm{CH}_{4}$ moiety. The fragments at $m / z 434.2325,448.2486$ and 607.2807 for compounds 10, 11 and 13 were generated 


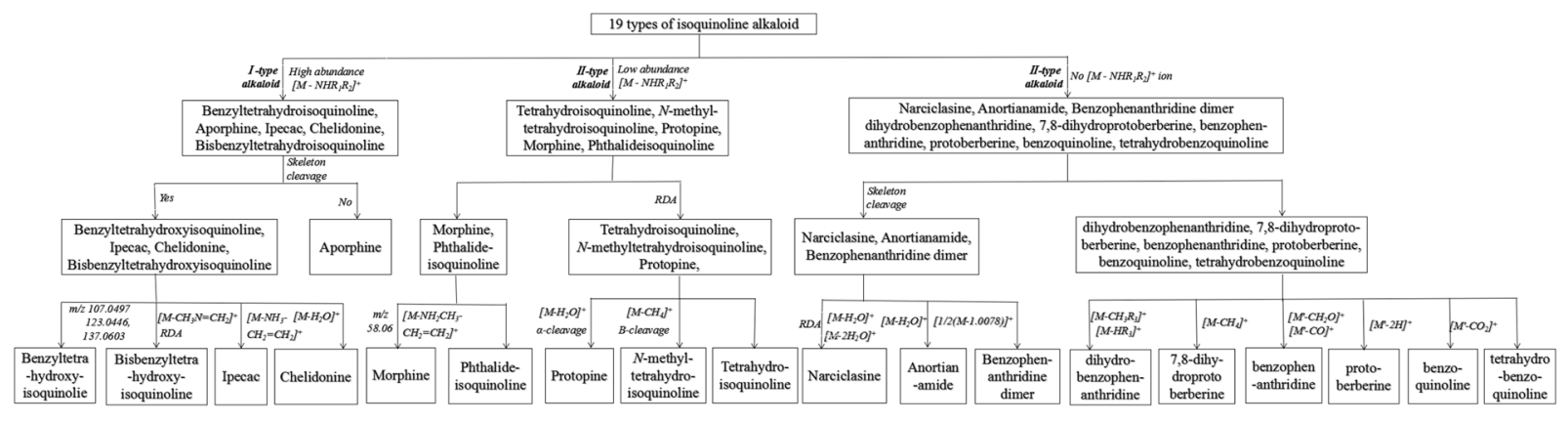

Figure 4. The proposed flowchart for categorization of 19 types of isoquinoline alkaloid.

by the loss of $\mathrm{a} \mathrm{CH}_{4}$ molecule from the ions at $m / z 450.2633,464.2797$ and 623.3121 (Fig. 2(b,d)) respectively. Alkaloids with methylenedioxy groups could produce some product ions by loss of a $\mathrm{CO}$ or $\mathrm{CH}_{2} \mathrm{O}$ moiety from their precursor ions. In the MS/MS spectrum of alkaloid 12 (Fig. S1), the molecular ion peak at $m / z 275.0683$ was observed, corresponding to loss of a $\mathrm{CH}_{2} \mathrm{O}$ moiety from the precursor ion at $\mathrm{m} / z 305.0785$, and subsequent loss of a $\mathrm{CO}$ and $\mathrm{CH}_{2} \mathrm{O}$ moiety leading to formation of fragment ions at $m / z 247.0737$ and 217.0627 was also detected (Fig. 2(c) $)^{14,15,22,26,27}$.

Benzyltetrahydroisoquinoline, aporphine, ipecac, chelidonine and bisbenzyltetrahydro- isoquinoline alkaloid could be well categorized by their characteristic fragmentation patterns. The MS/MS spectra of benzyltetrahydroisoquinoline, ipecac, chelidonine and bisbenzyltetrahydro- isoquinoline alkaloid show a wide spectral range because of the cleavage of these alkaloid skeletons. However, the MS/MS spectra of aporphine alkaloids (compounds 8 and 9, Fig. S1) was different from the above four alkaloid types because of the conjugated structure. Characteristic fragments below $\mathrm{m} / \mathrm{z} 200$ were not observed, and the main product ions were formed by the loss of substituent groups (Fig. S1) ${ }^{14-16}$. From the ESI-MS/MS spectra of benzyltetrahydroisoquinoline alkaloids (1-7), a series of fragment ions at $\mathrm{m} / z$ 107.0448, 107.0448, 123.0434, 137.0592, 123.0440, 123.0446 and 137.0593 were detected, which corresponded to $\beta$-cleavage of the skeleton (Fig. 2(a)). These characteristic ions play an important role in the discrimination of the other three types ${ }^{12-15}$. The fragmentation behaviours of bisbenzyltetrahydroisoquinoline were different from those of benzyltetrahydroisoquinoline alkaloids. The above characteristic fragment ions were not observed in the MS/MS spectrum of alkaloid 13 (Fig. S1). However, the fragment at $m / z 580.2694$ $\left(\left[\mathrm{M}-\mathrm{CH}_{3} \mathrm{~N}=\mathrm{CH}_{2}\right]^{+}\right.$) was formed by retro-Diels-Alder (RDA) fragmentation at the B-ring of the protonated molecule at $m / z 623.3121$ (Fig. 2(d)). The fragmentation pathway was regarded as a characteristic marker for bisbenzyltetrahydroisoquinoline alkaloids ${ }^{27}$. In the MS/MS spectra of alkaloids 10 and $\mathbf{1 1}$, most of the fragment ions were produced by cleavage of the alkaloid skeleton. However, the characteristic ions at $\mathrm{m} / z 422.2318$ and 436.2492 were formed by successive loss of $\mathrm{NH}_{3}$ and $\mathrm{CH}_{2}=\mathrm{CH}_{2}$ moieties from the protonated molecular ion at $m / z 467.2898$ and 481.3063, respectively, which were regarded as a diagnostic fragmentation pattern for ipecac-type alkaloids(Fig. 2(b) $)^{26}$. The MS/MS spectra of chelidonine alkaloids can be well distinguished from other alkaloid types by the presence of $\left[\mathrm{M}-\mathrm{H}_{2} \mathrm{O}\right]^{+}$ions. In the MS/MS spectrum of alkaloid 12 (Fig. S1), the ion at $\mathrm{m} / z 336.1210$ was formed by the neutral loss of $\mathrm{H}_{2} \mathrm{O}$ molecule from the protonated molecular ion at $\mathrm{m} / z 354.1313^{22}$. The proposed flowchart for identification of each alkaloid type is shown in Fig. 4. The proposed fragmentation behaviours of benzyltetrahydro- isoquinoline, aporphine, ipecac, chelidonine and bisbenzyltetrahydroisoquinoline alkaloid are shown in Fig. $2^{10,12-16,22,26,27}$.

Fragmentation behaviours of tetrahydroprotoberberine, $\mathrm{N}$-methyltetrahydroprotoberberine, protopine, morphinan and phthalideisoquinoline. In the MS/MS spectra of tetrahydroprotoberberine, $N$-methyltetrahydroprotoberberine, protopine, morphinan and phthalideisoquinoline alkaloid (type II), a series of low-abundance fragment ions $(\mathrm{m} / \mathrm{z} 311.1273,309.1121,307.0987,325.1467,323.1290,339.1601$, $307.0952,309.1121,311.1284,323.1287,311.1280,323.0898,339.1179,255.1010,269.1306$ and 383.1143 for alkaloids 14-29, respectively) were detected, which were rarely reported in previous studies. These fragment ions were generated by the loss of the $\mathrm{NHR}_{1} \mathrm{R}_{2}$ moiety from the protonated molecules (Fig. S1). These lowabundance fragments play a diagnostic role in distinguishing between type I alkaloids, which always produced a high-abundance $\left(\left[\mathrm{M}-\mathrm{NHR}_{1} \mathrm{R}_{2}\right]^{+}\right)$ion in their MS/MS spectra. Taking alkaloids $\mathbf{1}$ and $\mathbf{1 4}$ as examples, the high-abundance $\left[\mathrm{M}-\mathrm{NH}_{3}\right]^{+}$ion at $\mathrm{m} / z 269.1180$ (ppm 2.97), which was easily observed in the MS/MS spectrum of alkaloid 1 (Fig. 5), was produced by the loss of an $\mathrm{NH}_{3}$ moiety from the protonated molecule at $\mathrm{m} / z 286.1445$ $(\mathrm{ppm} 2.44)^{15,17}$. However, the low-abundance $\left[\mathrm{M}-\mathrm{NH}_{3}\right]^{+}$fragment at $m / z 311.1273(\mathrm{ppm}-1.60)$, which was difficult to detect in the MS/MS spectrum of alkaloid 14 (Fig. 5), was also formed by the loss of an $\mathrm{NH}_{3}$ moiety from the protonated molecule at $\mathrm{m} / \mathrm{z} 328.1542(\mathrm{ppm}-0.30)$.

In the MS/MS spectra of tetrahydroprotoberberine, $N$-methyltetrahydroprotoberberine, and protopine, the characteristic fragment ions mainly appear below $m / z 230$, which corresponds to RDA reaction, and are regarded as diagnostic fragmentation behaviour to discriminate morphinan and phthalideisoquinoline-type alkaloids ${ }^{15}$. The unique fragments of protopine-type alkaloids were formed mainly by the neutral loss of $\mathrm{H}_{2} \mathrm{O}$ from the $[\mathrm{M}+\mathrm{H}]^{+}$ion (e.g, $\mathrm{m} / z 336.1212$ and 352.1531 for alkaloids 25 and 26, respectively) and $\alpha$-cleavage of the skeleton (e.g, $\mathrm{m} / z 165.0539$ and 181.0850 for alkaloids 25 and 26, respectively) (Fig. 6(a)). These characteristic fragmentation patterns distinguish protopine from tetrahydroprotoberberine and $N$-methyltetrahydroprotoberberine ${ }^{10,14,15}$. Tetrahydro-protoberberine showed fragmentation pathways similar to $\mathrm{N}$-methyltetrahydroprotoberberine. 

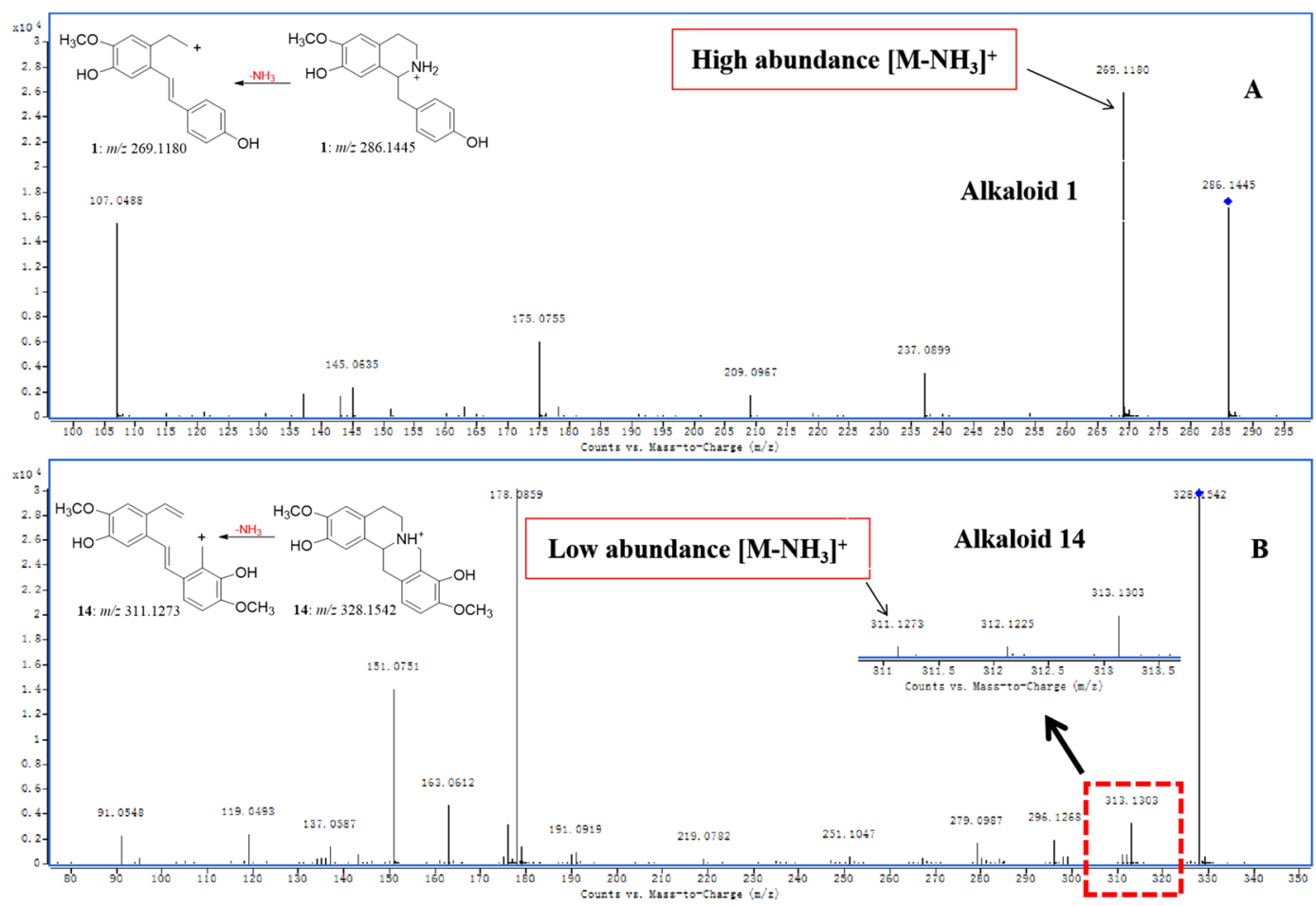

Figure 5. The MS/MS spectra of alkaloids $\mathbf{1}(\mathbf{A})$ and $\mathbf{1 4}(\mathbf{B})$ and the corresponding $\left[\mathrm{M}-\mathrm{NH}_{3}\right]^{+}$fragment ion.

However, low- abundance $\left[\mathrm{M}-\mathrm{CH}_{4}\right]^{+}$ions $(\mathrm{m} / \mathrm{z} 322.1091,324.2292,326.1354,338.1493$ and 326.1378 for alkaloids 20-24, respectively) were observed for $\mathrm{N}$-methyltetrahydroprotoberberine alkaloids, which were formed by loss of the $\mathrm{N}$-methyl and vicinal hydrogen atom from the protonated molecules. In addition, the B-ring cleavage reaction (forming fragments at $m / z 176.0704$ and 190.0861 for alkaloids $\mathbf{1 6}$ and 20, respectively) played an important role in determining the substituent group on the $\mathrm{N}$-atom (Fig. 6(a)). Therefore, the tetrahydroprotoberberine and $\mathrm{N}$-methyltetrahydroprotoberberine alkaloids could be categorized by the presence of $\left[\mathrm{M}-\mathrm{CH}_{4}\right]^{+}$ ions and B-ring cleavage reactions ${ }^{14,15}$. In the MS/MS spectra of morphine and phthalideisoquinoline-type alkaloids, the fragments were formed mainly by the loss of some substituent groups and cleavage of the alkaloid skeleton (Fig. 6(b,c)). Fragment ions at $m / z 227.0716$ and 241.0844 were observed for alkaloids 27 and 28 , respectively, by the loss of $\mathrm{NH}_{2} \mathrm{CH}_{3}$ and $\mathrm{CH}_{2}=\mathrm{CH}_{2}$ moieties from the protonated structure. The ion at $\mathrm{m} / z$ 58.06 was observed for both alkaloids, corresponding to the 1,2-cleavage reaction (Fig. 6(b)). The morphine and phthalideisoquinoline-type alkaloids could be characterized by these characteristic ions and fragmentation behaviours ${ }^{23}$. The proposed flowchart for identification of these five alkaloid types is shown in Fig. 4. The proposed fragmentation behaviours of tetrahydroprotoberberine, $N$-methyltetrahydroprotoberberine, protopine, morphinan and phthalideisoquinoline alkaloid are shown in Fig. $6^{8,10,12-15,17,23,25}$.

Fragmentation behaviours of narciclasine, anortianamide, benzophenanthridine dimer, dihydrobenzophenanthridine, 7,8-dihydroprotoberberine, protoberberine, benzophenanthridine, benzoquinoline and tetrahydrobenzoquinoline. In the MS/MS spectra of narciclasine, anortianamide, benzophenanthridine dimer, dihydrobenzophenanthridine, 7,8-dihydroprotoberberine, protoberberine, benzophenanthridine, benzoquinoline and tetrahydrobenzoquinoline alkaloid, the characteristic $\left[M-N H R_{1} R_{2}\right]^{+}$fragment ions could not be detected due to the existence of a $p-\pi$ conjugated system in their structure. This result was obtained by comparing the MS/MS spectra of alkaloids 1-29 with those of alkaloids 30-66 (type III) on the basis of their structural characteristics. Taking alkaloids 20 and $\mathbf{5 8}$ as examples (Fig. 7), the low- abundance characteristic ion at $\mathrm{m} / z 307.0971$ (ppm 0) was observed in the MS/MS spectrum of alkaloid 20, corresponding to the loss of a $\mathrm{NH}_{2} \mathrm{CH}_{3}$ radical $\left(\mathrm{R}_{1}=\mathrm{H}, \mathrm{R}_{2}=\mathrm{CH}_{3}\right.$ ) from the protonated molecule at $\mathrm{m} / z 338.1377$ (ppm -2.95). However, in the MS/MS spectrum of alkaloid 58, the $\left[\mathrm{M}-\mathrm{NH}_{2} \mathrm{CH}_{3}\right]^{+}$fragment ion was not detected (a suspected $\left[\mathrm{M}-\mathrm{NH}_{2} \mathrm{CH}_{3}\right]^{+}$fragment at $\mathrm{m} / z 305.1039$ was observed; however, its reached $75.7 \mathrm{ppm}$ ). The difference between the two structure types is that alkaloid $\mathbf{5 8}$ has a double bond between C-13 and C-13a and form the $p-\pi$ conjugated system with the $N$-moiety (Fig. 7). It is difficult to escape the conclusion that the existence of a $p-\pi$ conjugated system could lead to the absence of a characteristic $\left[M-N H R_{1} R_{2}\right]^{+}$fragment ion. The missing $\left[\mathrm{M}-\mathrm{NHR}_{1} \mathrm{R}_{2}\right]^{+}$fragments played a diagnostic role in the discrimination of type I and II alkaloids (Fig. 4). The absence of $\left[\mathrm{M}-\mathrm{NHR}_{1} \mathrm{R}_{2}\right]^{+}$fragment ions of type III alkaloids were observed, and corresponding reason was proposed for the first time.

From the MS/MS spectra of narciclasine, anortianamide and benzophenanthridine dimer, some lower $\mathrm{m} / \mathrm{z}$ region fragment ions (compared with the protonated molecules) were generated mainly by the cleavage of the alkaloid skeleton. The characteristic fragmentation behaviour played an important role in distinguishing 


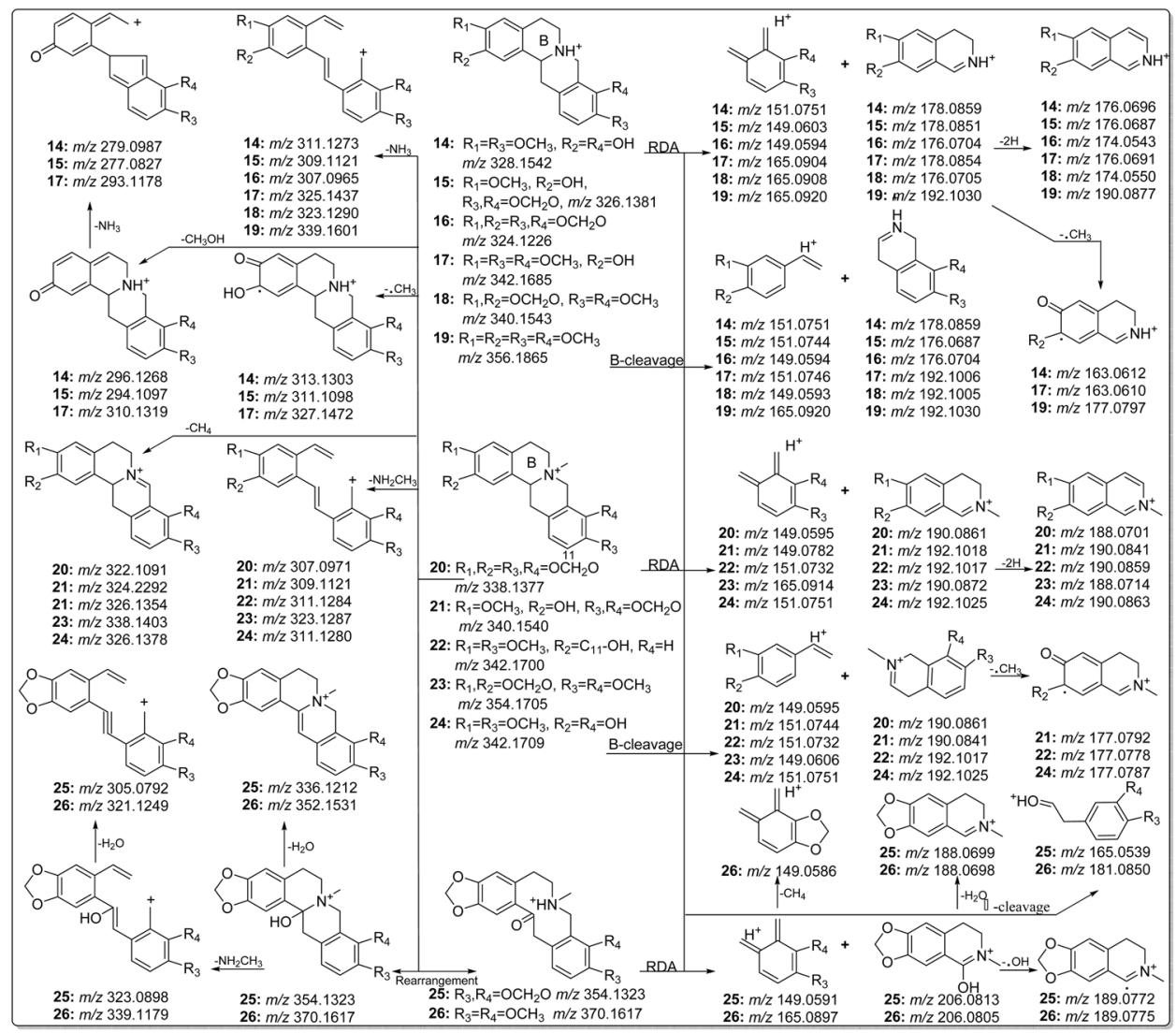

$a$ Tetrahydroprotoberberine, $N$-methyltetrahydroprotoberberine and protopine alkaloids

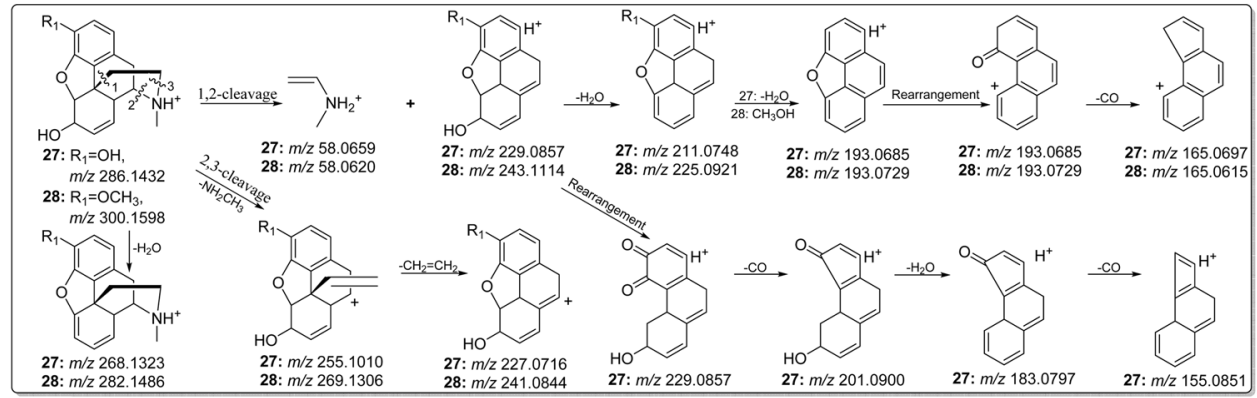
$b$ Morphine alkaloids

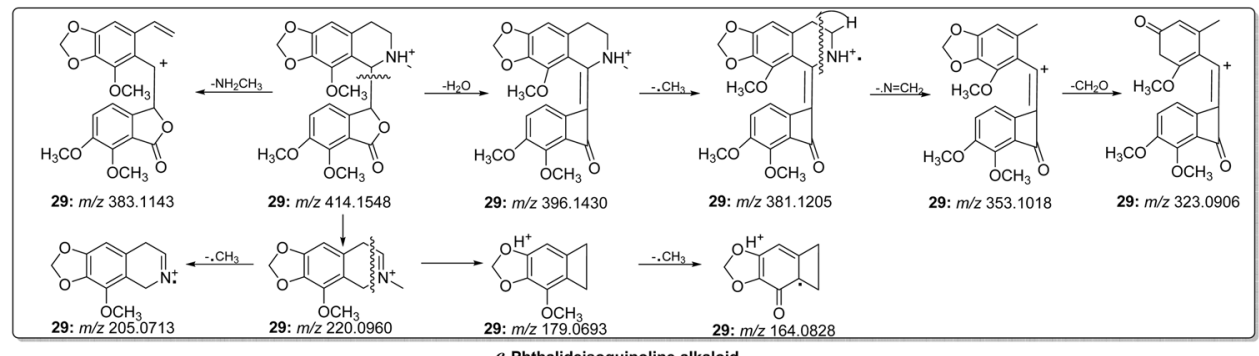

Figure 6. The proposed fragmentation behaviours of tetrahydroprotoberberine, $N$ methyltetrahydroprotoberberine and protopine (a), morphinan (b), and phthalideisoquinoline (c).

dihydrobenzophenanthridine, 7,8-dihydroprotoberberine, benzophenanthridine, protoberberine, benzoquinoline and tetrahydrobenzoquinoline-type alkaloids ${ }^{14,15,24}$. In the MS/MS spectrum of narciclasine (30) (Fig. S1), the ions at $m / z 290.0672$ and 272.0536 were formed, corresponding to successively neutral loss of $\mathrm{H}_{2} \mathrm{O}$ molecules from the protonated ion at $\mathrm{m} / z 308.0750$ (Fig. 8(a) $)^{24}$. However, in the MS/MS spectrum of anortianamide (31) (Fig. S1), only neutral loss of a $\mathrm{H}_{2} \mathrm{O}$ molecule from the ion $\mathrm{m} / z 382.1285$ and a fragment ion at $\mathrm{m} / z 364.1164$ were observed (Fig. 8(b)). In addition, the predominant ion at $\mathrm{m} / z 248.0542$ was observed in the mass spectrum of alkaloid 30 corresponding to the RDA reaction. The benzophenanthridine dimer alkaloid could be easily categorized by the presence of $[1 / 2(\mathrm{M}-1.0078)]^{+}$ions (Fig. 8(c)). These characteristic fragmentation behaviours and 


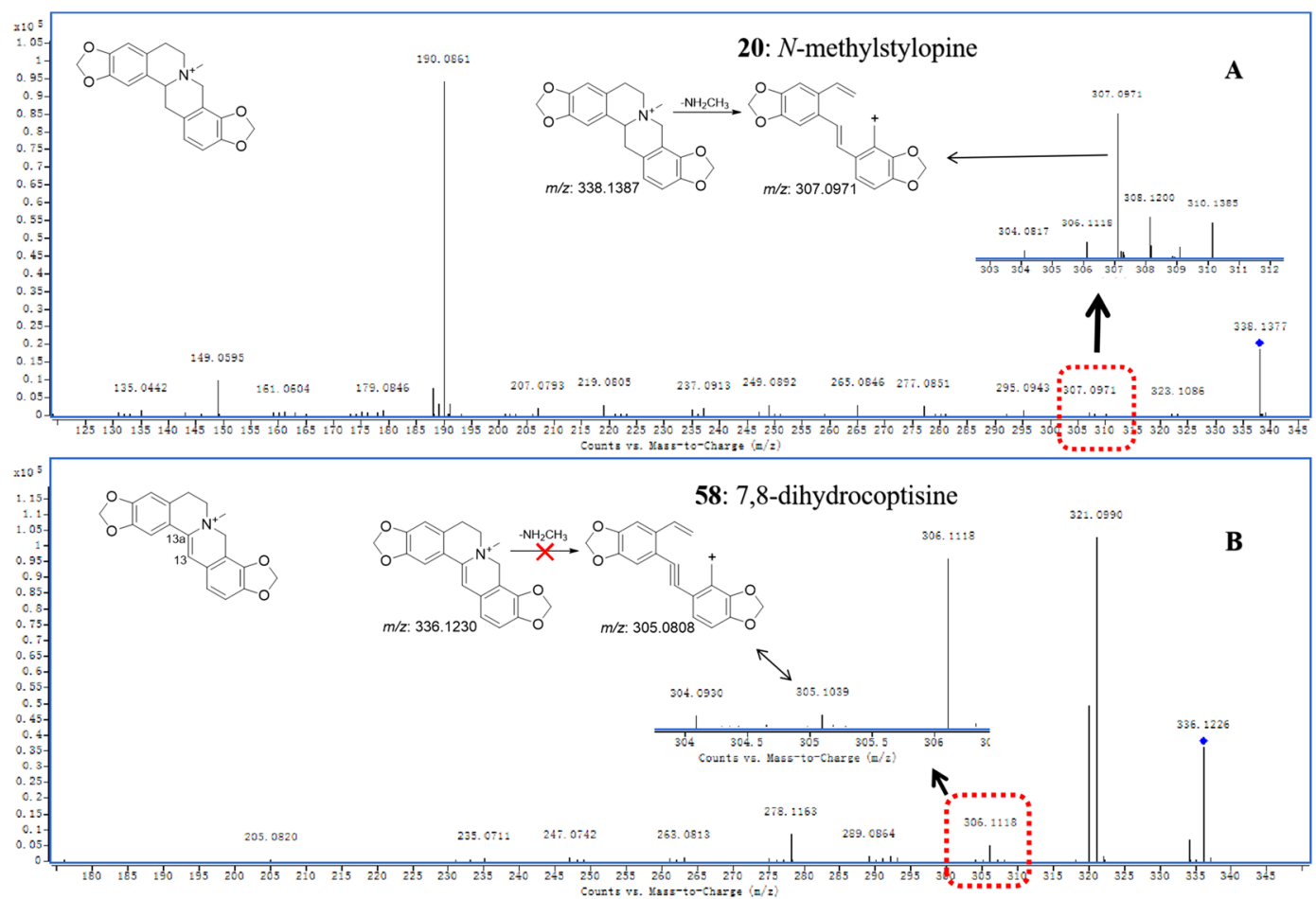

Figure 7. The MS/MS spectra of alkaloids $20(\mathbf{A})$ and $\mathbf{5 8}(\mathbf{B})$.
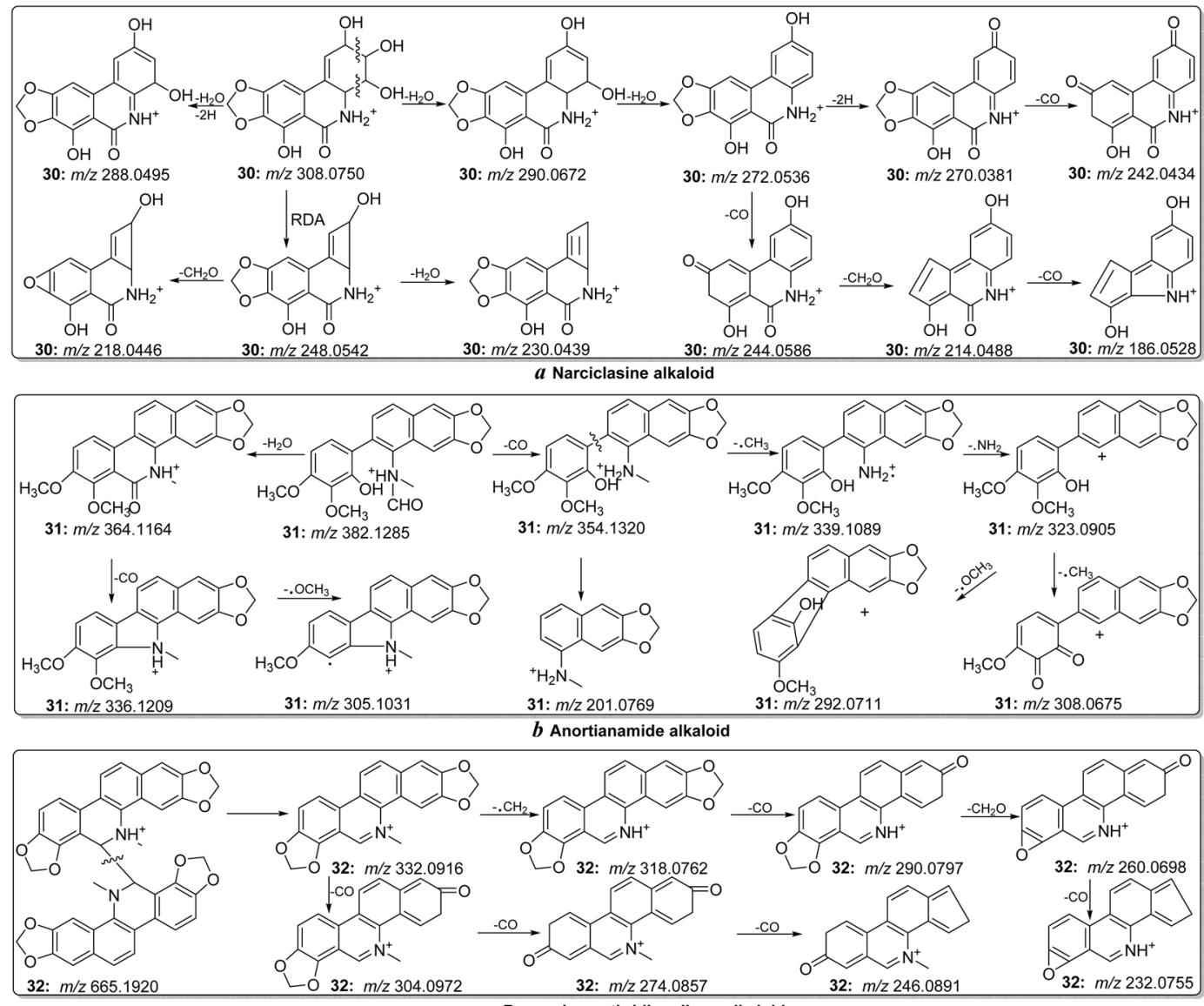

Figure 8. The proposed fragmentation behaviours of narciclasine (a), anortianamide (b) and benzophenanthridine dimer (c). 

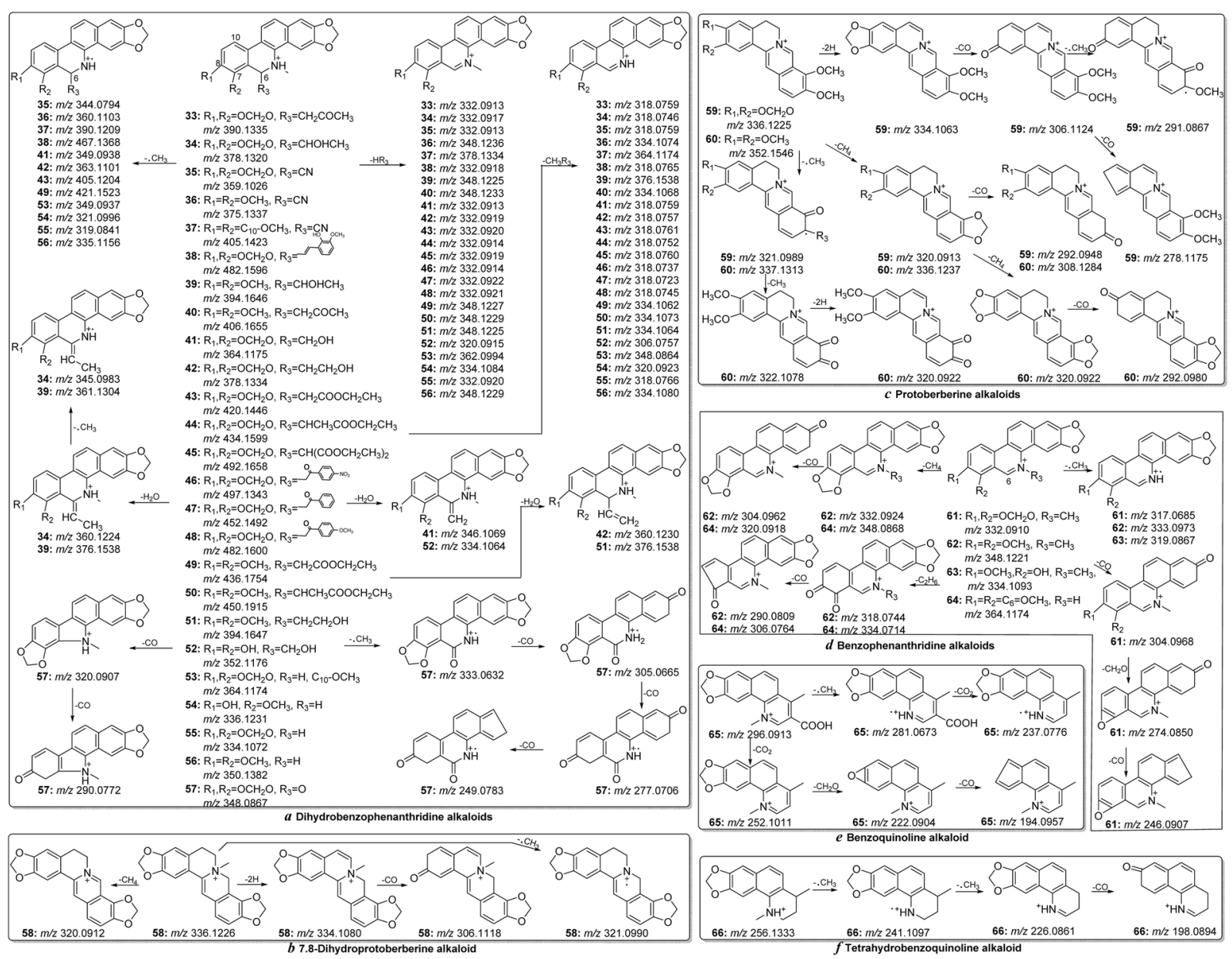

Figure 9. The proposed fragmentation behaviours of dihydrobenzophenanthridine (a), 7,8-dihydroprotoberberine (b), protoberberine (c), benzophenanthridine (d), benzoquinoline (e) and tetrahydrobenzoquinoline (f).

fragments played an important role in the discrimination of narciclasine, anortianamide and benzophenanthridine dimer-types alkaloids. The proposed flowchart for identification of these three alkaloid types is shown in Fig. 4. The proposed fragmentation behaviours of these alkaloids are shown in Fig. $8^{14,15,24}$.

The MS/MS spectra of dihydrobenzophenanthridine, 7,8-dihydroprotoberberine, benzophenanthridine, protoberberine, benzoquinoline and tetrahydrobenzoquinoline(Fig. S1) are different from those of other alkaloid types. The fragments were formed mainly by the loss of some substituent groups because of the conjugated structure. The $\left[\mathrm{M}-\mathrm{HR}_{3}\right]^{+}$and $\left[\mathrm{M}-\mathrm{CH}_{3} \mathrm{R}_{3}\right]^{+}$fragment ions were observed for the dihydrobenzophenanthridine-type alkaloids corresponding to loss of the substituent at C-6 $\left(\mathrm{R}_{3}\right)$ with vicinal groups $\left(\mathrm{H} \text { and } \mathrm{CH}_{3}\right)^{14,15,21}$. Taking alkaloid 33 as an example, the fragments at $m / z 332.0913(-1.20 \mathrm{ppm})$ and $318.0759(-0.62 \mathrm{ppm})$ were simultaneously formed by the loss of $\mathrm{CH}_{3} \mathrm{COCH}_{3}\left(\left[\mathrm{M}-\mathrm{HR}_{3}\right]^{+}\right)$and $\mathrm{CH}_{3} \mathrm{CH}_{2} \mathrm{COCH}_{3}\left(\left[\mathrm{M}-\mathrm{CH}_{3} \mathrm{R}_{3}\right]^{+}\right)$moieties, respectively, from the protonated molecule at $m / z 390.1335(-0.25 \mathrm{ppm})$ (Fig. $9(\mathrm{a}))^{15}$. The loss of $N$-methyl and vicinal $\mathrm{H}$-atom from the ion at $m / z 336.1226$ and the formation of $\left[\mathrm{M}-\mathrm{CH}_{4}\right]^{+}$fragments $(\mathrm{m} / z 320.0912)$ were detected for 7,8-dihydroprotoberberine (58), which were regarded as characteristic fragmentation behaviours of 7,8-dihydroprotoberberine-type alkaloids(Fig. 9(b)). The [fragment ion-2H] ${ }^{+}$ions $(e . g, m / z 334.1063$ and 320.1266 for alkaloids $\mathbf{5 9}$ and $\mathbf{6 0}$, respectively) were detected for protoberberine-type alkaloids, which corresponded to a loss of the $\mathrm{H}$-atoms at C-5 and C-6, forming the conjugated system ${ }^{8,15}$ (Fig. 9 (c)). However, the characteristic ion was also observed for benzophenanthridine, which always appeared along with the loss of a CO moiety and formation of [fragment ion- $\left.\mathrm{CH}_{2} \mathrm{O}\right]^{+}$ions $(e . g, \mathrm{~m} / z 274.0850$ and 302.0809 for alkaloids 61 and 62 , respectively) (Fig. 9(d) $)^{15}$. In the MS/MS spectrum of alkaloid 65 (benzoquinoline alkaloid) (Fig. S1), the [fragment ion- $\left.\mathrm{CO}_{2}\right]^{+}$ions $(\mathrm{m} / z 252.1011$ and 237.0776) were detected, corresponding to the existence of the $-\mathrm{COOH}$ group (Fig. $9(\mathrm{e}))^{28}$. The six types of alkaloids could be characterized by their special fragmentation behaviours and fragment ions (the fragmentation pathway of tetrahydrobenzoquinoline alkaloid (66) is provided in Fig. 9(f)). The proposed flowchart for identification of each alkaloid type is shown in Fig. 4. The proposed fragmentation behaviours of these alkaloids are shown in Fig. $9^{8,14,15,21,29}$.

In addition to the above characteristic fragmentation patterns, some common fragmentation behaviours were also observed for these types of isoquinoline alkaloids. Alkaloids with vicinal methoxy and hydroxy, vicinal methoxy and methylenedioxy groups could form the $\left[\mathrm{M}-\mathrm{CH}_{3} \mathrm{OH}\right]^{+},\left[\mathrm{M}-\mathrm{CH}_{4}\right]^{+}$and $\left[\text {fragment ion- } \mathrm{CH}_{2} \mathrm{O}\right]^{+}$or 

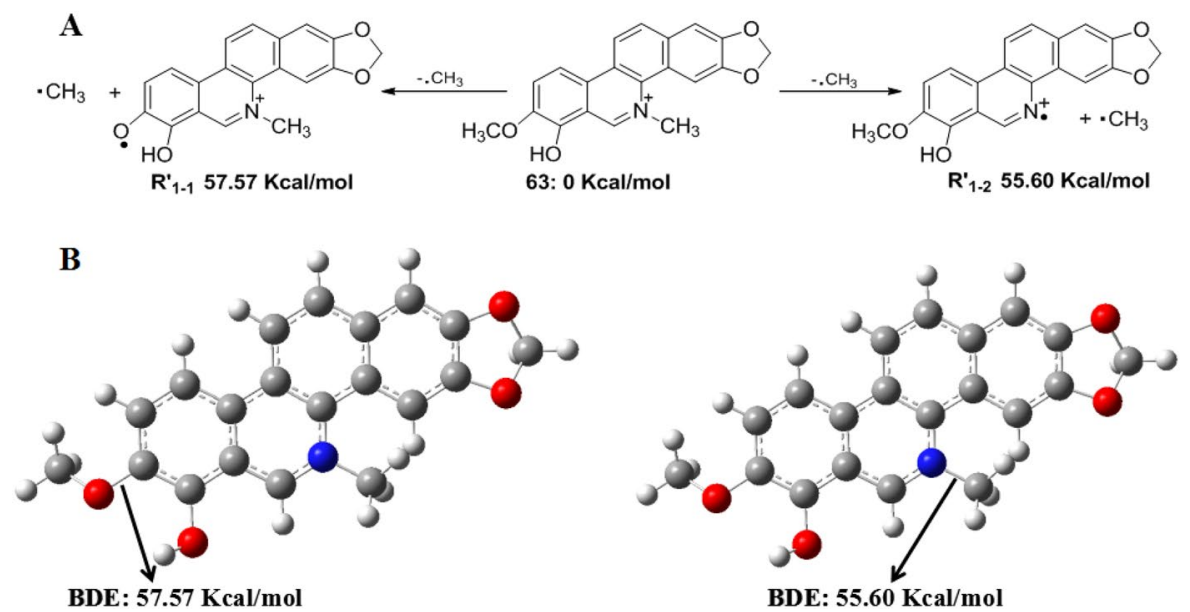

Figure 10. Two theoretical calculation methods $(\mathbf{A}, \mathbf{B})$ for the loss of a $\mathrm{CH}_{3}$ radical from alkaloid 63.

$[\text { fragment ion-CO }]^{+}$fragment ions, respectively. These characteristic pathways have been discussed. In addition, alkaloids with methoxy groups could produce [fragment ion- $\left.\mathrm{CH}_{3}\right]^{+}$fragments by loss of a $\mathrm{CH}_{3}$ radical, and continual neutral ejection of a CO molecule and formation [fragment ion- $\left.\mathrm{CH}_{3}-\mathrm{CO}\right]^{+}$ions were also observed ${ }^{15}$. In the MS/MS spectra of alkaloids 59 and 60 (Fig. S1), the ions at $m / z 291.0867$ and 322.1078 were formed by the loss of a $\mathrm{CH}_{3}$ radical from the precursor ions at $m / z 306.1124$ and 337.1313, respectively. Subsequently, continual ejection of a CO molecule led to the formation of fragments at $m / z 263.0809$ and 294.1128 $8^{8}$. Alkaloid with quaternary $\mathrm{N}$-methyl group could form the $\left[\mathrm{M}-\mathrm{CH}_{3}\right]^{+}$fragment ion. In the MS/MS spectra of alkaloids $\mathbf{6 1}$ and $\mathbf{6 5}$ (Fig. S1), the fragments at $m / z 317.0685$ and 281.0673 were presented by the loss of a $\mathrm{CH}_{3}$ radical from quaternary $N$-centre ${ }^{15}$.

Some interesting common fragmentation pathways draw our attention. Taking alkaloid $\mathbf{6 3}$ as an example, the loss of a $\mathrm{CH}_{3}$ radical from the mother ion at $\mathrm{m} / z 334.1093$ could give the high-abundance fragment ion at $\mathrm{m} / z$ 319.0867. Normally, among $\mathrm{N}-\mathrm{CH}_{3}$ and $\mathrm{O}-\mathrm{CH}_{3}$, it was difficult to demonstrate which one was favoured regarding the loss of the $\mathrm{CH}_{3}$ moiety in the MS spectrum. Herein, two calculation methods were used to predict the more reasonable fragmentation pathway. Two hypothetical losses of the $\mathrm{CH}_{3}$ radical from methoxyl at C-8 or $\mathrm{N}$-methyl in the mother ion would give $\mathbf{R}_{\mathbf{1 - 1}}$ and $\mathbf{R}_{\mathbf{1 - 2}}$ fragmentation, respectively (Fig. 10(A)). The relative energy of $\mathbf{R}_{\mathbf{1 - 2}}$ was $55.60 \mathrm{kcal} / \mathrm{mol}$, which was lower than that of $\mathbf{R}_{\mathbf{1 - 1}}$, indicated that $\mathbf{R}_{\mathbf{1 - 2}}$, was more stable to give high-abundance fragment ions. In addition to the above method, the bond dissociation energies of $\mathrm{N}-\mathrm{CH}_{3}$ and $\mathrm{O}-\mathrm{CH}_{3}$ were calculated (Fig. 10(B)). The dissociation energy of $\mathrm{N}-\mathrm{CH}_{3}$ was $55.60 \mathrm{kcal} / \mathrm{mol}$, which was $1.97 \mathrm{kcal} / \mathrm{mol}$ lower than that of $\mathrm{O}-\mathrm{CH}_{3}$. This result suggested that the bond dissociation between the $\mathrm{N}$-atom and $\mathrm{CH}_{3}$ was favoured. The calculation results indicated that the mother ion at $\mathrm{m} / z 334.1093$ tends to lose the $\mathrm{CH}_{3}$ moiety from the $\mathrm{N}$-atom and subsequently gave the high-abundance molecular ion peak at $\mathrm{m} / \mathrm{z}$ 319.0867 .

\section{Summary}

In this study, the MS/MS fragmentation behaviours of 66 compounds, which belong to 19 types of isoquinoline alkaloids, were investigated on a Q-TOF/MS spectrometer in $\mathrm{ESI}^{+}$mode. These isoquinoline alkaloids could be divided into three categories primarily by the characteristic $\left[\mathrm{M}-\mathrm{NHR}_{1} \mathrm{R}_{2}\right]^{+}$fragment ion. Type I and II alkaloids (compounds 1-29) could form high- and low- abundance $\left[M-N H R_{1} R_{2}\right]^{+}$ions, respectively. However, the characteristic fragments were not generated for type III alkaloids (compounds 30-66) because of the existence of a $p-\pi$ conjugated system in its structure. Furthermore, each type of alkaloid was classified by its characteristic MS/MS fragmentation patterns and fragment ions (Fig. 4). The high-abundance $\left[M-N H R_{1} R_{2}\right]^{+}$fragments of benzyltetrahydroisoquinoline and aporphine-type alkaloid have been reported in some previous studies but rarely mentioned for ipecac, chelidonine, and bisbenzyltetrahydroisoquinoline-type alkaloids (type I) ${ }^{15,16}$. The low-abundance $\left[\mathrm{M}-\mathrm{NHR} \mathrm{R}_{2}\right]^{+}$ions of type II alkaloids were observed and reported for the first time. The mechanism of formation of $\left[\mathrm{M}-\mathrm{NHR}_{1} \mathrm{R}_{2}\right]^{+}$fragment ions was also investigated by computational chemistry. The reason for the absence of characteristic $\left[\mathrm{M}-\mathrm{NHR} \mathrm{R}_{2}\right]^{+}$fragment ions of type III alkaloids was proposed. In addition, five common fragmentation pathways were observed and summarized for isoquinoline alkaloids: (1) Alkaloids with vicinal methoxy and hydroxy groups could produce the characteristic fragments by neutral loss of a $\mathrm{CH}_{3} \mathrm{OH}$ molecule. (2) Alkaloids with vicinal methoxy groups could form the characteristic ions by eliminating of a $\mathrm{CH}_{4}$ moiety. (3) Alkaloids with methylenedioxy groups could generate interesting fragments by loss of a $\mathrm{CH}_{2} \mathrm{O}$ moiety or CO molecule. (4) Alkaloids with methoxy groups could produce distinctive ions by ejection of a methyl radical and CO molecule. (5) Alkaloids with quaternary $\mathrm{N}$-methyl groups could form the $\left[\mathrm{M}-\mathrm{CH}_{3}\right]^{+}$fragment ion ${ }^{10,15}$. These characteristic fragmentation pathways of isoquinoline alkaloids provided a solid foundation for the structural elucidation of similar metabolites in plant-derived medicines. 


\section{Experiment}

Materials and reagents. HPLC-grade formic acid and acetonitrile were purchased from Merck (Darmstadt, Germany) and ROE (Newark, New Castle, USA), respectively. Deionized water was purified using a Milli-Q system (MA, USA). The 22 references, 3'-hydroxy- $N$-methylcoclaurine (3), reticuline (4), norlaudanosoline (5), 6-O-methylnorlaudanosoline (6), norreticuline (7), magnoflorine (8), isocorydine (9), cephaeline (10), emetine (11), chelidonine (12), tetrandrin (13), stylopine (16), tetrahydrocolumbamine (17), canadine (18), tetrahydropalmatine (19), $N$-methylcheilanthifoline (21), phellodendrine (22), morphine (27), codeine (28), noscapine (29), narciclasine (30), and palmatine chloride (60), were purchased from the National Institutes for Food and Drug Control (Beijing, China). The 29 reference alkaloids, namely, $N$-methylscoulerine (24), protopine (25), allocryprotopine (26), anortianamide (31), sanguinarine dimer (32), 6-acetonyldihydrosanguinarine (33), $\left(1^{\prime} \rightarrow 6\right)$-hydroxy- ethyldihydrosanguinarine (34), 6-cyanodihydrosanguinarine (35), 6-cyanodihydrochelerythrine (36), 6-cyanodihydrochelilutine (37), maclekarpine $\mathrm{E}(38),\left(1^{\prime} \rightarrow 6\right)$-hydroxyethyldihydrochelerythrine (39), 6-acetonyldihydrochelerythrine (40), 6-hydroxymethylsanguinarine (41), 6-hydroxyethyldihydro- chelerythrine (51), 6-hydroxymethyl-7,8-demethylenedihydrochelerythrine (52), dihydrochelirubine (53), 8-demethyldihydrochelerythrine (54), dihydrosanguinarine (55), dihydrochelerythrine (56), oxysanguinarine (57), 7,8-dihydrocoptisine (58), berberine (59), sanguinarine (61), chelerythrine (62), 7-demethylchelerythrine (63), 6-methoxy-norchelerythrine (64), 2,3-methylenedioxy-7,10-dimethyl- 8-carboxyl-benzoquinoline (65), and 2,3-methylenedioxy-7,10-dimethyl-7,8,9,10-tetrahydro- benzoquinoline (66), were separated and identified from the plant-derived medicine named Macleaya cordata by our laboratory. The remaining 15 references, namely, coclaurine (1), $N$-methylcoclaurine (2), scoulerine (14), cheilanthifoline (15), $N$-methylstylopine (20), $\mathrm{N}$-methyltetrahydroberberine (23), 6-ethoxy-dihydrosanguinarine (42), ethyl 2'-(dihydrosanguinarine-6-yl) acetate (43), ethyl $2^{\prime}$-(dihydro- sanguinarine-6-yl)propanoate(44), ethyl $2^{\prime}$-(dihydrosanguinarine-6-yl)maonlate (45), 1'-(4-nitrophenyl)-2'-(dihydro-sanguinarine-6-yl)ethanone(46), 1'-phenyl-2'-(dihydrosanguinarine-6-yl) ethanone(47), $1^{\prime}$-(4-methoxyphenyl)-2'-(dihydro-sanguinarine-6-yl)ethanone (48), ethyl $2^{\prime}$-(dihydrochelerythrine-6-yl)acetate (49), and ethyl 2'-(dihydrochelerythrine-6-yl)propanoate (50), were synthesized in our laboratory. The above 66 references (Table S1) were used to investigate the fragmentation behaviours of 19 types of isoquinoline alkaloids.

Reference preparation and analysis. Approximately $2.0 \mathrm{mg}$ alkaloid was dissolved in $10 \mathrm{~mL}$ methanol by an ultrasonic bath for $5 \mathrm{~min}$. A portion of the methanol solution was filtered through a $0.22 \mu \mathrm{m}$ nylon membrane. A $2 \mu \mathrm{L}$ sample was injected into Q-TOF/MS directly by an Agilent 1290 high-performance liquid chromatography (HPLC) system (Agilient Technologies, USA) consisting of an auto-sampler, a rapid resolution binary pump, a vacuum degasser, a thermostatted column compartment and a tunable UV detector. However, the chromatographic column was not equipped with the HPLC system for rapidly obtaining the MS and MS/MS data of references.

Q-TOF/MS conditions. Mass spectra were acquired using a 6530 Q-TOF/MS accurate-mass spectrometer (Agilent Technologies, Palo Alto, CA, USA) equipped with an ESI source in positive ion mode. The conditions of the Q-TOF-MS were optimized as follows: sheath gas temperature: $350^{\circ} \mathrm{C}$; gas temperature: $300{ }^{\circ} \mathrm{C}$; nebulizer pressure: $35 \mathrm{psi}$; sheath gas flow: $11 \mathrm{~L} / \mathrm{min}$; drying gas: $8 \mathrm{~L} / \mathrm{min}$; fragmentor voltage: $175 \mathrm{~V}$; skimmer voltage: $65 \mathrm{~V}$; capillary voltage: $3500 \mathrm{~V}$. The TOF mass spectrometry was calibrated in $\mathrm{ESI}^{+}$mode before sample analysis using reference masses at $m / z 121.0508$ and 922.0097 to obtain high-accuracy mass measurements. The MS/MS experiments were performed using variable collision energy $(10-50 \mathrm{eV})$, which was optimized for each individual reference.

Theoretical calculations. All theoretical calculations for geometries of the neutral and protonated molecules, as well as the product ions, were performed by using the B3LYP function in combination with the 6-31 G(d) basis set in the Gaussian 03 package of programs. An unrestricted open-spell calculation (UB3LYP) was used for odd electron ions. The candidate structures of protonated molecules, fragment ions, neutral molecules and transition states were optimized by calculating the force constants, while no symmetry constraints were imposed in the process of optimization ${ }^{29,30}$. All optimized structures were subjected to vibrational frequency analysis for zero-point energy correction ${ }^{29,31}$. The energies of each optimized structure are the sum of electronic and thermal energies. The optimized structures were visualized by Gauss View (version 3.09).

Received: 22 August 2019; Accepted: 23 December 2019;

Published online: 20 January 2020

\section{References}

1. Hagel, J. M. \& Facchini, P. J. Benzylisoquinoline alkaloid metabolism: a century of discovery and a brave new world. Plant Cell Physiol. 54, 647-672 (2013).

2. Sato, F., Inui, T. \& Takemura, T. Metabolic engineering in isoquinoline alkaloid biosynthesis. Curr. Pharmaceut. Biotechnol. 8, 211-218 (2007)

3. Brahmachari, G. Bioactive natrual products. Wiley-VCH, India (2013).

4. Iranshahy, M., Quinn, R. J. \& Iranshahi, M. Biologically active isoquinoline alkaloids with drug-like properties from the genus Corydalis. Rsc Adv. 45, 15900-15913 (2014).

5. Diamond, A. \& Desgagnépenix, I. Metabolic engineering for the production of plant isoquinoline alkaloids. Plant Biotechnol. J. 14, 1319-1328 (2016).

6. Zhou, G. S. et al. Comprehensive analysis of 61 characteristic constituents from Siraitiae fructus using ultrahigh-pressure liquid chromatography with time-of-flight mass spectrometry. J. Pharm. Biom. Anal. 125, 1-14 (2016).

7. Qing, Z. X. et al. Systematic identification of flavonols, flavonol glycosides, triterpene and siraitic acid glycosides from Siraitia grosvenorii using high-performance liquid chromatography/quadrupole-time-of-flight mass spectrometry combined with a screening strategy. J. Pharm. Biom. Anal. 138, 240-248 (2017). 
8. Zhang, J. et al. Systematic screening and characterization of tertiary and quaternary alkaloids from corydalis yanhusuo W.T. Wang using ultra-performance liquid chromatography-quadrupole-time-of-flight mass spectrometry. Talanta 78, 513-522 (2009).

9. Qing, Z. X. et al. An improved separation method for classification of Macleaya cordata from different geographical origins. Anal. Methods 7, 1866-1871 (2015).

10. Jeong, E. K. et al. Identification of structurally diverse alkaloids in Corydalis species by liquid chromatography/electrospray ionization tandem mass spectrometry. Rapid Commun. Mass Spectrom. 26, 1661-1674 (2012).

11. Deevanhxay, P. et al. Simultaneous characterization of quaternary alkaloids, 8-oxoprotoberberine alkaloids, and a steroid compound in Coscinium fenestratum by liquid chromatography hybrid ion trap time-of-flight mass spectrometry. J. Pharmaceut. Biomed. Anal. 50, 413-425 (2009).

12. Liu, Q. X. et al. Establishment of a search library about benzylisoquinoline alkaloids based on selective separation on the binaphthyl column and standard analysis on C18 column. J. Sep. Sci. 35, 3317-3325 (2012).

13. Schmidt, J. et al. Poppy alkaloid profiling by electrospray tandem mass spectrometry and electrospray FT-ICR mass spectrometry after [ring $-{ }^{13} \mathrm{C}_{6}$ ]- tyramine feeding. Phytochemistry $\mathbf{6 8}, 189-202(2007)$.

14. Qing, Z. X. et al. Structural speculation and identification of alkaloids in Macleaya cordata fruits by high-performance liquid chromatography/quadrupole-time-of-flight mass spectrometry combined with a screening procedure. Rapid Commun. Mass Spectrom. 28, 1033-1044 (2014).

15. Qing, Z. X. et al. Systematic identification of alkaloids in Macleaya microcarpa fruits by liquid chromatography tandem mass spectrometry combined with the isoquinoline alkaloids biosynthetic pathway. J. Pharmaceut. Biomed. Anal. 103, 26-34 (2015).

16. Stévigny, C. et al. Key fragmentation patterns of aporphine alkaloids by electrospray ionization with multistage mass spectrometry. Rapid Commun. Mass Spectrom. 18, 523-528 (2004).

17. Zuo, Z. et al. Tissue-specific metabolite profiling of benzylisoquinoline alkaloids in the root of Macleaya cordata by combining lasermicrodissection with ultra-high performance liquid chromatography/tandem mass spectrometry. Rapid Commun. Mass Spectrom. 31, 397-410 (2017).

18. Zhang, Y. F. et al. Characterization of isoquinoline alkaloids, diterpenoids and steroids in the Chinese herb Jin-Guo-Lan (Tinospora sagittata and Tinospora capillipes) by high-performance liquid chromatography/electrospray ionization with multistage mass spectrometry. Rapid Commun. Mass Spectrom. 20, 2328 (2006).

19. Wang, D. W., Liu, Z. Q., Guo, M. Q. \& Liu, S. Y. Structural elucidation and identification of alkaloids in Rhizoma Coptidis by electrospray ionization tandem mass spectrometry. J. Mass Spectrom. 39, 1356-1365 (2004).

20. Cai, M. et al. Rapid structural characterization of isomeric benzo[c]phenanthridine alkaloids from the roots of Zanthoxylum nitidium by liquid chromatography combined with electrospray ionization tandem mass spectrometry. Rapid Commun. Mass Spectrom. 21, 1931-1936 (2007)

21. Qing, Z. X., Cheng, P. \& Zeng, J. G. Research progress on mass spectral fragmentation behaviour of alkaloids in Macleaya cordata. Chinese Traditional and Herbal. Drugs 44, 2929-2939 (2013).

22. Yang, P. et al. Identification of isoquinoline alkaloids in Chelidonium majus by HPLC-Q-TOF/MS. Mod. Chin. Med. 19, 174-182 (2017).

23. Zhu, W. X., Yang, J. Z., Liu, Y. F. \& Sun, Z. L. Confirmation on poppy characteristic ingredients in foodstuffs by quadrupole tandem orbitrap high-resolution mass spectrometry. J. Instrum. Anal. 34, 495-501 (2015).

24. Katoch, D., Kumar, S., Kumar, N. \& Singh, B. Simultaneous quantification of Amaryllidaceae alkaloids from Zephyranthes grandiflora by UPLC-DAD/ESI-MS/MS. J. Pharmaceut. Biomed. Anal. 71, 187-192 (2012).

25. Nagy, L. et al. Fragmentation study of noscapine derivatives under electrospray conditions. Rapid Commun. Mass Spectrom. 28, 822-828 (2014).

26. Sun, L. et al. Rapid detection of alkaloids in ipecac by direct analysis in real time tandem mass spectrometry (DART-MS/MS). China J. Chin. Mater. Med. 37, 1426-1430 (2012).

27. Gao, P. et al. Fragmentation pathways of the fangchinoline by ESI-MS/MS. J. Shengyang Pharm. Univ. 29, 208-211 (2012).

28. Qing, Z. X. et al. Mass spectrometry-guided isolation of two new benzoquinoline alkaloids from Macleaya cordata. Nat. Prod. Res. 30, 1030-1035 (2016).

29. Guo, C. et al. An experimental and computational investigation on the fragmentation behavior of enaminones in electrospray ionization mass spectrometry. J. Mass Spectrom. 45, 1291-1298 (2010).

30. You, Z. S., Guo, C. \& Pan., Y. J. An experimental and theoretical study on fragmentation of protonated $N$-(2-pyridinylmethyl)indole in electrospray ionization mass spectrometry. Rapid Commun. Mass Spectrom. 26, 2509-2516 (2012).

31. Butler, M., Mañez, P. A. \& Cabrera., G. M. An experimental and computational study on the dissociation behavior of hydroxypyridine $\mathrm{N}$-oxides in atmospheric pressure ionization mass spectrometry. J. Mass Spectrom. 45, 536-544 (2010).

\section{Acknowledgements}

This work was supported by Hunan Provincial Innovation Foundation for Postgraduate (CX2017B424) and the National Key Research and Development Program of China (2016YFD0501308). We thank Doctor Rui Wang (School of Environment and Energy, South China University of Technology) for providing the calculational platform.

\section{Author contributions}

P.C. and J.G.Z. conceived and organized the research. Z.X.Q., Y.Q.X., L.Y.Y., J.H.L., X.Q.H. and Z.S.T. performed the experiment. Z.X.Q. performed the data analysis and wrote the manuscript.

\section{Competing interests}

The authors declare no competing interests.

\section{Additional information}

Supplementary information is available for this paper at https://doi.org/10.1038/s41598-019-57406-7.

Correspondence and requests for materials should be addressed to P.C. or J.Z.

Reprints and permissions information is available at www.nature.com/reprints.

Publisher's note Springer Nature remains neutral with regard to jurisdictional claims in published maps and institutional affiliations. 
(c) (i) Open Access This article is licensed under a Creative Commons Attribution 4.0 International License, which permits use, sharing, adaptation, distribution and reproduction in any medium or format, as long as you give appropriate credit to the original author(s) and the source, provide a link to the Creative Commons license, and indicate if changes were made. The images or other third party material in this article are included in the article's Creative Commons license, unless indicated otherwise in a credit line to the material. If material is not included in the article's Creative Commons license and your intended use is not permitted by statutory regulation or exceeds the permitted use, you will need to obtain permission directly from the copyright holder. To view a copy of this license, visit http://creativecommons.org/licenses/by/4.0/.

(C) The Author(s) 2020 